\title{
CENTRO DE FORMAÇÃO DE RECURSOS HUMANOS EM TRANSPORTES URBANOS - CEFTRU
}

\author{
José Augusto Abreu Sá Fortes \\ Mestrado de Transportes Urbanos' \\ Universidade de Brasília
}

\section{O PROJETO}

O Centro de Formação de Recuros Humanos em Transportes Urbanos CEFTRU é um projeto bilateral entre os governos brasileiro e japonês, de iniciativa do Mestrado em Transportes Urbanos da Universidade de Brasília (UnB), sob os auspícios de Ministério das Relações Exteriores - Agência Brasileira de Cooperação - MRE/ ABC e da Japan International Cooperation Agency - JICA.

O projeto visa a constituição e a posterior consolidação de um centro de excelência para a capacitação e a reciclagem de pessoal de nível superior, médio e fundamental em transoprtes urbanos, envolvendo as áreas de planejamento, gestão e operação do sistema, com impactos sócio-econômicos para as populações urbanas. O Centro tem por objetivo melhorar a qualificação de pessoal envolvido com os transportes urbanos da administração pública e privada, englobando o território nacional, nas áreas de meioambiente, informática e ensino a distância e tecnologia de transportes e tráfego. Para a consecução desses objetivos serão constituídos três laboratórios (de computação e ensino a distância, de tecnologia de transporte e tráfego e de monitoramento e controle ambiental), além do treinamento de professores e técnicos brasileiros no Japão e a cooperação técnica internacional visando a absorção de conhecimentos avançados referentes a diversas temáticas ligadas ao setor.

OCEFTRU, apesar de ser uma iniciativa da UnB, deverá envolver instituições privadas e públicas, a nível municipal, estadual e federal. Daí a importância do projeto que prevê a associação de várias entidades relacionadas com a área de transportes urbanos, dentre as quais Unversidades, Ministé- 
rios, Secretarias de Estado e empresas privadas, que através de programas específicos de formação, capacitação e reciclagem pretende qualificar profissionais para atuar no setor. Em relação ao setor público, os técnicos serão capacitados nas funções relativas ao sistema viário e ao transporte público e privado. Dentro do programa de treinamento para o setor privado, pretende-se abordar as questões relativas à administração e gestão das empresas de transporte urbano, visando a adaptação destas às novas formas de produção e organização do trabalho. O aumento de produtividade e a melhoria da qualidade dos serviços ofertados terão reflexos diretos em custos e, consequentemente, nas tarifas. A criação de uma instituição específica e de excelência para atender esse mercado potencial resultará na capacitação de técnicos, coordenadores, diretores, etc., responsáveis pelo planejamento e a gestão dos transportes urbanos nas cidades, fortalecendo os órgãos locais. Além da formação e reciclagem de pessoal do setor público, o Centro capacitará os gerentes e operadores em micro, pequenas, médias e grandes empresas de transportes urbanos, melhorando a qualidade do serviço ofertado.

O projeto prevê a utilização de recursos computacionais e de telecomunicações para a formação destes recursos humanos através de métodos e técnicas modernas de educação. Neste sentido está prevista a instalação de um laboratório de ensino a distância, estruturado com equipamentos de informática e de transmissão e recepção de imagem que, interligados, permitirão a constituição de uma rede de informações, fundamental para a operacionalização das técnicas modernas de formação de pessoal.

O montante dos recursos a serem aplicados no projeto está estimado em aproximadamente US\$ $8,600,000.00$, dos quais US\$ 3,200,000.00 serão a contrapartida da instituição executora e US $\$ 5,400,000.00$ provenientes de fontes externas, destinados à construção do edifício sede, à aquisição de equipamentos e à formação dos técnicos que atuarão junto ao Centro. Para cada US\$1.00 aplicado pelo lado brasileiro, o Centro receberá a fundo perdido do Governo Japonês, o correspondente a US\$2.00.

\section{JUSTIFICATIVA}

As questões relativas aos transportes urbanos nas cidades brasileiras são inúmeras e complexas, a começar pela política para o setor, o planejamento, os investimentos, a operação, a gestão e a organização do sistema, a nível 
público e privado. No início dos anos 70, o crescimento acelerado e desordenado das áreas urbanas levou a administração pública a pensar, pela primeira vez, os problemas do espaço urbano. Neste contexto, o setor de transportes urbanos, entendido como um ponto crítico do sistema pelo efeito catalisador que produz sobre a utilização do solo e a importância do transporte público nos deslocamentos, foi tratado específica e estrategicamente nos aspectos intra-urbanos da política elaborada para o setor. $O$ estado, enquanto agente promotor do desenvolvimento econômico e social, através da melhor distribuição da renda, da estabilização da economia e da alocação de recursos, estruturou-se para intervir na área de transportes urbanos. Assim em 1973, na Empresa Brasileira de Planejamento de Transportes - GEIPOT foi constituído o Conselho de Transportes Urbanos, com o objetivo de elaborar uma política para os transportes urbanos. Alguns anos depois, esse Conselho foi transformado em Departamento de Transportes Urbanos, inaugurando efetivamente a fase de estudos, planos e projetos na área em várias cidades brasileiras. Entretanto, as modificações estruturais e conjunturais ocorridas nesta década, levaram o Governo Federal a criar um órgão específico para promover, coordenar e executar a Política Nacional de Transportes Urbanos. A Empresa Brasileira de Transportes Urbanos - EBTU assume a responsabilidade da elaboração das diretrizes nacionais da política para o setor, além de assegurar a coordenação entre os diversos órgãos estaduais e municipais de transportes e a promoção dos investimentos para a área. As diretrizes traçadas pelo Estado basicamente objetivaram reduzir as conseqüências fatais do crescimento das cidades, como por exemplo a degradação da qualidade de vida, os riscos econômicos, a deseconomia de escala, etc. Além dessas atribuições, a EBTU ficou encarregada do desenvolvimento científico e tecnológico, especialmente da formação de pessoal para atuar no setor público e privado.

Recentemente, o Governo Federal, seguindo a tendência mundial de definição das políticas econômicas com base nas teorias clássicas, transferiu todas as suas funções aos estados e municípois ou ao setor privado. A política de se desencarregar das funções dos transportes urbanos, extinguindo agências, privatizando empresas e descentralizando a foṛmulação e execução das atividades para os níveis administrativos regionais e locais, além do financiamento de infra-estruturas e dos serviços de transporte, tem causado a indefinição de rumos para área.

Com a extinção da EBTU, estados, municípios e o próprio setor privado foram privados de todo este suporte técnico, científico e financeiro. Se no 
que tange as agências governamentais, a infra-estrutura técnico-científica para o setor de transportes apresentou tal panorama de desmobilização, as entidades de ensino e pesquisa tentam sensibilizar a sociedade e dar suporte, principalmente às instituições públicas, no tocante às questões relativas ao transporte. Daí, a reversão desse quadro, com o Governo Federal reestruturando, junto ao Ministério dos Transportes e ao GEIPOT, a área de transportes urbanos.

Entretanto, a ausência de técnicos e pesquisadores nestes órgãos, leva o estado a solicitar constantemente o auxílio das universidades e centros de pesquisa em transportes urbanos para darem suporte à resolução dos problemas da área. Estas instituições estão demasiadamente concentradas na região sudeste (por exemplo: COPPE/UFRJ, PUC-RJ, IME, ITA, USP), permanecendo vastas regiões do país com suas demandas de formação de recursos humanos a diversos níveis (incluindo a educação informal) e de desenvolvimento científico e tecnológico praticamente inatendidas. Prevêse que existe um mercado potencial para o treinamento da ordem de $20 \mathrm{mil}$ pessoas/ano ligadas diretamente às atividades de transportes urbanos.

As atividades do Centro deverão apresentar um intenso impacto no ambiente externo, nacional e regional, inclusive cooperando intimamente com programas governamentais. Os efeitos estão assegurados, na medida em que Brasília sedia órgãos governamentais federais, assim como representações de governos locais e entidades internacionais (PNUD, Banco Mundial, OIT) e igualmente importantes confederações empresariais (CNT, NTU, NTC, Rodonal, etc.) do setor. Além deste horizonte nacional, há de se contemplar também a cooperação técnica com outros países em desenvolvimento, especialmente da América Latina e da África, onde há necessidade de formação de recursos humanos.

A ligação do Centro com o órgão da administração pública poderia eventualmente não estar nas prioridades de uma nova administração o que prejudicaria sobremaneira os objetivos do projeto. Portanto, a implantação do Centro no campus da Universidade de Brasília justifica-se pela continuidade do projeto, pois a mudança da administração na universidade não ocasionará a ruptura da proposta. 